\title{
Is right axillary artery cannulation safe in type $A$ aortic dissection with involvement of the innominate artery?
}

\author{
Bartosz Rylski, MD, ${ }^{\mathrm{a}}$ Martin Czerny, MD,${ }^{\mathrm{a}}$ Friedhelm Beyersdorf, MD, PhD, ${ }^{\mathrm{a}}$ Fabian Alexander Kari, MD, ${ }^{\mathrm{a}}$ \\ Matthias Siepe, MD, ${ }^{\mathrm{a}}$ Hideo Adachi, MD, PhD, ${ }^{\mathrm{b}}$ Atsushi Yamaguchi, MD, PhD, ${ }^{\mathrm{b}}$ Ryo Itagaki, MD, ${ }^{\mathrm{b}}$ and \\ Naoyuki Kimura, $\mathrm{MD}, \mathrm{PhD}^{\mathrm{b}}$
}

\begin{abstract}
Objective: In patients with acute type A aortic dissection involving the innominate artery, it is unclear whether right axillary artery cannulation for arterial inflow is safe. We evaluated the surgical outcomes of patients with dissected innominate artery according to different arterial cannulation sites.

Methods: From 2005 to 2014, of 416 patients with acute type A aortic dissection and preoperative computed tomography angiography in 2 centers, 186 (aged $63 \pm 13$ years; $43 \%$ were female; 95\% with DeBakey type I) had dissected innominate artery $(84 \%, 9 \%$, and $7 \%$ involving its entire length or more or less than half of its length, respectively). Neurologic complications, in-hospital mortality, and survival were compared between patients with right axillary $(\mathrm{N}=84)$ and non-right axillary $(\mathrm{N}=102)$ cannulation sites. Median follow-up was 30 months (range, 0-130 months).
\end{abstract}

Results: In-hospital mortality was $9.5 \%$ and $10.8 \%(P=.97)$ for patients with right and non-right axillary cannulation, respectively. Seven patients $(8.3 \%)$ with right axillary cannulation and 9 patients $(8.8 \% ; P=.89)$ with non-right axillary cannulation had a new-onset postoperative stroke. The axillary artery was cannulated (although dissected) in 8 patients. None of them had a new-onset stroke or died perioperatively. The innominate artery remodeling was observed on follow-up computed tomography in $12 \%$ of right axillary cases and $14 \%$ of non-right axillary cases $(P=.82)$. Survival did not differ between right axillary and non-right axillary cases, and measured 92\% $\pm 3 \%$ versus $87 \% \pm 4 \%$ and $85 \% \pm 5 \%$ versus $73 \% \pm 9 \%$ at 1 and 5 years, respectively $(\log$ rank, $P=.29)$.

Conclusions: The right axillary artery is safe to cannulate for arterial inflow in patients with type A aortic dissection with dissected innominate artery. (J Thorac Cardiovasc Surg 2016;152:801-7)

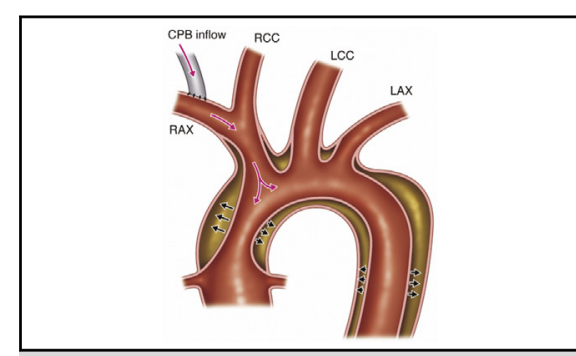

Axillary artery cannulation in case of dissected innominate artery.

\section{Central Message}

The RAX artery is safe to cannulate for arterial inflow in patients with type A dissection with dissected innominate artery.

\section{Perspective}

This study evaluates the safety of RAX artery cannulation in case of a dissected innominate artery. We did not observe inferior outcomes in these patients when compared with other cannulation sites. These results may encourage cardiac surgeons to use the RAX artery for arterial inflow for the heart-lung machine regardless of innominate artery involvement in the dissection process.

See Editorial Commentary page 808 .
Selecting the ideal arterial cannulation site for cardiopulmonary bypass (CPB) in patients with acute Stanford Type A dissection is critical. Currently advocated routes

\footnotetext{
From the aDepartment of Cardiovascular Surgery, Heart Centre Freiburg University, Freiburg, Germany; and ${ }^{b}$ Department of Cardiovascular Surgery, Jichi Medical University, Saitama Medical Centre, Saitama, Japan.

Read at the 29th European Association for Cardio-Thoracic Surgery Annual Meeting in Amsterdam, Netherlands, October 3-7, 2015. Winner of the Society of Thoracic Surgeons/European Association for Cardio-Thoracic Surgery 2015 Award.

Received for publication Feb 27, 2016; revisions received April 14, 2016; accepted

for publication April 29, 2016; available ahead of print May 26, 2016.

Address for reprints: Bartosz Rylski, MD, Department of Cardiovascular Surgery,

Heart Centre Freiburg University, Hugstetter Str. 55, 79106 Freiburg, Germany

(E-mail: bartosz.rylski@universitaets-herzzentrum.de).

$0022-5223 / \$ 36.00$

Copyright (c) 2016 by The American Association for Thoracic Surgery

http://dx.doi.org/10.1016/j.jtcvs.2016.04.092
}

include the axillary, common carotid, innominate, and femoral arteries, as well as the ascending aorta or apex of the left ventricle.

Axillary artery cannulation was first described by Villard and colleagues ${ }^{2}$ in 1976 and reintroduced in the 1990s by Sabik and colleagues. ${ }^{3}$ Evidence is growing that axillaryartery cannulation is superior to other cannulation sites because it preserves antegrade flow in the descending aorta,

Scanning this $\mathrm{QR}$ code will take you to supplemental figure for this article. 


\section{Abbreviations and Acronyms \\ $\mathrm{CPB}=$ cardiopulmonary bypass \\ $\mathrm{CT}=$ computed tomography \\ $\mathrm{RAX}=$ right axillary}

thereby reducing the risk for embolization and facilitating the administration of selective cerebral perfusion during aortic arch repair. ${ }^{4-6}$ These arguments led the authors of "2014 European Society of Cardiology Guidelines on the diagnosis and treatment of aortic diseases" to recommend that the axillary artery be considered the first choice for cannulation in surgery of the aortic arch and in type A dissection (class of recommendation I, level of evidence $\mathrm{C}$ ).

Axillary-artery cannulation in patients with a dissected innominate artery is controversial. Supra-aortic branches are involved in the dissection process in up to $37 \%$ of patients presenting with acute type A dissection. ${ }^{8}$ It is unclear whether right axillary (RAX) artery cannulation for arterial inflow in these patients is safe. It remains unknown what happens with both lumina of the dissected innominate artery during retrograde CPB blood flow after axillary-artery cannulation and whether there is a significant risk of false lumen expansion, true lumen collapse, and multiorgan malperfusion in this scenario. Our aim was to evaluate the efficacy and safety of RAX artery cannulation for aortic repair in patients with acute type A dissection with a dissected innominate artery.

\section{MATERIALS AND METHODS Patient Population}

The institutional review committees at both participating centers approved this study, and the need for informed consent was waived. The Saitama Medical Centre in Saitama (Japan) and the Heart Centre Freiburg University in Freiburg and Bad Krozingen (Germany) reviewed their aortic databases covering patients undergoing operation since January 2008 in Saitama and from January 2005 in Freiburg to December 2014. Among 469 patients with acute type A aortic dissection, 416 had undergone high-quality preoperative computed tomography (CT) angiography. The study cohort comprises 186 patients (129 Saitama and 57 Freiburg patients; aged $63 \pm 13$ years; $43 \%$ were female; $95 \%$ with DeBakey type I) with dissected innominate artery (Figure 1). The process involved the entire length or more or less than half of the innominate artery length in $84 \%$, $9 \%$, and $7 \%$ of cases, respectively. Patients presenting a RAX cannulation site for arterial inflow for $\mathrm{CPB}(\mathrm{N}=84)$ were compared with patients who underwent non-RAX $(\mathrm{N}=102)$ cannulation for arterial inflow. Neurologic complications, in-hospital mortality, and survival were compared.

\section{Surgical Approach}

All patients at both centers underwent emergency replacement of the entire ascending aorta. Proximal repair included resuspending the aortic valve, aortic valve replacement, aortic root replacement, or valve-sparing root replacement. Distal repair included isolated ascending, hemiarch, or total arch replacement depending on the entry tear location and aortic diameter, as described previously. ${ }^{9-12}$ Aortic arch surgery was performed in hypothermic circulatory arrest with selective cerebral perfusion in all patients and with

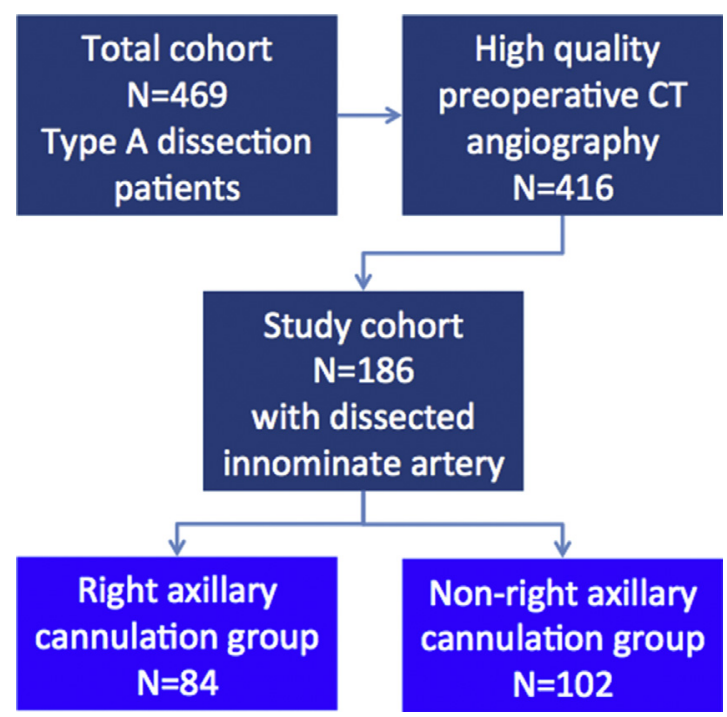

FIGURE 1. Flow of patient selection process. $C T$, Computed tomography.

open distal anastomosis. In the early years of the study, hypothermic arrest was induced at $18^{\circ} \mathrm{C}$. Currently, the temperature applied for hypothermic circulatory arrest ranges from $21^{\circ} \mathrm{C}$ to $25^{\circ} \mathrm{C}$ at both centers.

\section{Arterial Cannulation Site}

The ascending aorta, heart apex, supra-aortic, and femoral arteries were used for arterial inflow. In case of cardiogenic shock, femoral or apical (Saitama) cannulation was applied to promptly initiate CPB. In hemodynamically stable patients, femoral cannulation was preferred in the early study years, whereas axillary cannulation was favored later. The axillary artery was cannulated in all patients indirectly via a $10-\mathrm{mm}$ (Saitama) or 8-mm (Freiburg) prosthesis anastomosed end-to-side to the axillary artery. Patients with non-RAX were cannulated at the right femoral artery $(\mathrm{N}=36)$, heart apex $(\mathrm{N}=28)$, left carotid artery $(\mathrm{N}=10)$, left axillary artery $(\mathrm{N}=9)$, left femoral artery $(\mathrm{N}=5)$, ascending aortic $(\mathrm{N}=3)$, and right carotid artery $(\mathrm{N}=1)$. Two arterial cannulation sites were applied in 25 patients $(30 \%)$ with $\operatorname{RAX}(\mathrm{N}=21$ right femoral, $\mathrm{N}=2$ ascending aortic, $N=1$ heart apex, $N=1$ left femoral) and 9 patients $(9 \%)$ with non-RAX (3 right femoral and heart apex; 2 right femoral and left axillary; 2 right femoral and ascending aortic; 1 right femoral and left carotid; 1 left femoral and left axillary). The second arterial cannulation site was chosen (1) to provide adequate body perfusion if there was a high line pressure during heart-lung machine initiation with single arterial in-flow cannula or the cooling process was slow $(\mathrm{N}=2)$; (2) to achieve quicker cooling and rewarming if the patient was obese with a body mass index more than $30 \mathrm{~kg} / \mathrm{m}^{2}(\mathrm{~N}=8)$; (3) to improve the lower body perfusion if the patient presented with lower-limb ischemia $(\mathrm{N}=9)$; and (4) because of surgeon preferences $(\mathrm{N}=15)$.

\section{Patient Follow-up}

Surveillance follow-up data were obtained for all patients by contacting the patients' general practitioners, the patients themselves, and their family members via aortic clinic office visits. Patients were followed up a total of 543 patient-years, with a median follow-up among survivors of 2.5 (first quartile, 0.6; third quartile, 4.2) years. CT for arterial remodeling analysis was obtained in $96 \%$ between 3 and 12 months after discharge.

\section{Definitions}

Shock is defined as a systolic blood pressure less than $80 \mathrm{~mm} \mathrm{Hg}$ or any need for preoperative catecholamine therapy. Hemiarch is an open distal 
TABLE 1. Demographics and clinical presentation

\begin{tabular}{|c|c|c|c|c|}
\hline & All $(\mathbf{n}=186)$ & RAX cannulation $(n=84)$ & Non- $R A X$ cannulation $(n=102)$ & $P$ value \\
\hline Age (y) & $63(51 ; 71)$ & $60(51 ; 69)$ & $67(53 ; 74)$ & .033 \\
\hline$>80 \mathrm{y}$ & $14(7.5)$ & $5(6.0)$ & $9(8.8)$ & .646 \\
\hline Male gender & $107(57.5)$ & $55(65.5)$ & $52(51.0)$ & .066 \\
\hline \multicolumn{5}{|l|}{ Clinical presentation } \\
\hline Hypertension & $138(74.2)$ & $60(71.4)$ & $78(76.5)$ & .539 \\
\hline Diabetes mellitus & $10(5.4)$ & $5(6.0)$ & $5(4.9)$ & .992 \\
\hline Current smoker & $43(23.1)$ & $19(22.6)$ & $24(23.5)$ & .978 \\
\hline COPD & $10(5.4)$ & $6(7.1)$ & $4(3.9)$ & .520 \\
\hline Coronary artery disease & $7(3.8)$ & $3(3.6)$ & $4(3.9)$ & .793 \\
\hline Prior stroke & $13(7.0)$ & $4(4.8)$ & $9(8.8)$ & .428 \\
\hline Prior TND & $3(1.6)$ & $2(2.4)$ & $1(1.0)$ & .865 \\
\hline Previous cardiac surgery & 0 & 0 & 0 & \\
\hline MFS & $10(5.4)$ & $4(4.8)$ & $6(5.9)$ & .992 \\
\hline Bicuspid aortic valve & $4(2.2)$ & $1(1.2)$ & $3(2.9)$ & .756 \\
\hline DeBakey I & $176(94.6)$ & $79(94.0)$ & $97(95.1)$ & .992 \\
\hline Cardiogenic shock & $32(17.2)$ & $5(6.0)$ & $27(26.5)$ & $<.001$ \\
\hline Cardiac tamponade & $25(13.4)$ & $4(4.8)$ & $21(20.6)$ & .003 \\
\hline \multicolumn{5}{|l|}{ Malperfusion } \\
\hline At least 1 organ & $80(43.0)$ & $29(34.5)$ & $51(50.0)$ & .038 \\
\hline Coronary & $18(9.7)$ & $8(9.5)$ & $10(9.8)$ & .835 \\
\hline Cerebral & $39(21.0)$ & $13(15.5)$ & $26(25.5)$ & .137 \\
\hline Iliofemoral & $30(16.1)$ & $10(11.9)$ & $20(19.6)$ & .222 \\
\hline Gastrointestinal & $17(9.1)$ & $6(7.1)$ & $11(10.8)$ & .547 \\
\hline Renal & $14(7.5)$ & $5(6.0)$ & $9(8.8)$ & .646 \\
\hline Spinal & $2(1.1)$ & $1(1.2)$ & $1(1.0)$ & .565 \\
\hline
\end{tabular}

Categoric values are n (\%), and continuous values are median (first quartile; third quartile). RAX, Right axillary; COPD, chronic obstructive pulmonary disease; TND, temporary neurologic dysfunction; $M F S$, Marfan syndrome.

anastomosis with an excision of lesser curvature. Total arch is defined as reimplantation of 1 or more supra-aortic vessels. Respiratory failure is defined as mechanical ventilation more than 48 hours. Arterial remodeling is defined as a lack of dissection or intramural hematoma in the artery, which was dissected or had intramural hematoma at the initial CT angiography with an acute type A aortic dissection.

\section{Statistical Analysis}

Continuous data are presented as median (first quartile, third quartile); categoric variables are given as counts and percentages. To compare continuous variables, the Mann-Whitney rank-sum test was used. Categoric variables were compared using the Fisher exact test. Survival was analyzed via the Kaplan-Meier method and log-rank calculations.

Propensity score matching was used to adjust for baseline characteristics. Because of the relatively low number of patients, only the most clinically important variables were entered in the propensity score matching analysis. Selected variables were age, male gender, Marfan syndrome, cardiogenic shock, tamponade, at least 1 organ ischemia, aortic root replacement, and aortic arch replacement. On the basis of propensity scores, 69 pairs were successfully matched in a 1-to-1 manner. All statistical calculations were performed using SigmaPlot, version 12 (Systat Software, San Jose, Calif) and IBM SPSS Statistics, version 23.0 (IBM Corp, Armonk, NY).

\section{RESULTS}

\section{Demographics and Clinical Presentation}

Patient demographics are summarized in Table 1. Patients with RAX were significantly younger than patients with non-RAX (60 [51-69] years vs 67 [53-74] years;
$P=.03)$; however, the number of octogenarians was similar in both groups $(P=.65)$. We noted a trend toward more male patients in the RAX cannulation group $(P=.07)$. Patients with RAX and non-RAX presented similar cardiovascular risk profiles. The number of patients with cardiogenic shock was significantly lower in the RAX group $(6 \%$ vs $27 \%, P<.001)$. We observed a higher incidence of malperfusion syndrome of at least 1 organ in the non-RAX group (RAX $34.5 \%$ vs non-RAX $50.0 \%$, $P=.14)$.

\section{Dissection Anatomy}

A total of $94 \%$ of patients had DeBakey type I in the RAX group, and $95 \%$ of patients had DeBakey type I in the non-RAX group. The entire length of the innominate artery was dissected in more than two thirds of all patients. The RAX artery was less frequently dissected in the RAX group ( $10 \%$ vs $23 \%, P=.03)$. The dissection extension to peripheral arteries is presented in Table 2 .

\section{Surgical Management, Perioperative Outcome, and Survival}

Supracoronary ascending replacement and isolated ascending replacement without aortic arch repair were performed in the majority of RAX and non-RAX cases 
TABLE 2. Dissection extension into supra-aortic and iliac arteries at initial computed tomography

\begin{tabular}{|c|c|c|c|c|}
\hline & All $(n=186)$ & RAX cannulation $(n=84)$ & Non- $R A X$ cannulation $(n=102)$ & $P$ value \\
\hline \multicolumn{5}{|l|}{ Innominate artery } \\
\hline Entire length & $137(73.7)$ & $58(69.0)$ & $79(77.5)$ & .378 \\
\hline More than half length & $16(8.6)$ & $9(10.7)$ & $7(6.9)$ & .268 \\
\hline Less than half length & $33(17.7)$ & $17(20.2)$ & $16(15.7)$ & .538 \\
\hline RAX & $31(16.7)$ & $8(9.5)$ & $23(22.5)$ & .030 \\
\hline Right carotid & $110(59.1)$ & $45(53.6)$ & $65(63.7)$ & .211 \\
\hline Left carotid & $77(41.4)$ & $33(39.3)$ & $44(43.1)$ & .703 \\
\hline Left axillary & $68(36.6)$ & $30(35.7)$ & $38(37.3)$ & .949 \\
\hline Right iliac & $80(43.0)$ & $39(46.4)$ & $41(40.2)$ & .156 \\
\hline Left iliac & $86(46.2)$ & $40(47.6)$ & $46(45.1)$ & .386 \\
\hline
\end{tabular}

$R A X$, Right axillary.

$(80 \%$ vs $86 \%, P=.31$ and $63 \%$ vs $64 \%, P=.95$, respectively) (Table 3). CPB, aortic crossclamping, and hypothermic circulatory arrest times were similar in both groups. The RAX group underwent selective cerebral perfusion more frequently ( $57 \%$ vs $30 \%, P<.001)$.

There were no group differences with regard to re-thoracotomy for bleeding $(P=.88)$, renal failure $(P=.99)$, respiratory failure $(P=.57)$, and postoperative new-onset stroke $(P=.85)$. In-hospital mortality was $9.5 \%$ in the RAX group and $10.8 \%$ in the non-RAX group $(P=.97)$.

Survival did not differ between RAX and non-RAX groups, measuring $92 \% \pm 3 \%$ versus $87 \% \pm 4 \%$ and
$85 \% \pm 5 \%$ versus $73 \% \pm 9 \%$ at 1 and 5 years, respectively (log rank, $P=.29$ ) (Figure 2, $A$ ).

\section{Remodeling of Primarily Dissected Arteries}

No more dissections were detectable in the innominate artery at CT angiography follow-up in $12 \%$ of the RAX group and $14 \%$ of the non-RAX group $(P=.82)$. Remodeling of the RAX artery was observed in $13 \%$ of the RAX group and $17 \%$ of the non-RAX group $(P=1)$ with a primarily dissected RAX artery. The highest degree of remodeling was observed in the primarily dissected right carotid artery in the non-RAX group (26\%) (Figure E1). There was no significant difference between the RAX and

TABLE 3. Surgery for type A aortic dissection details and outcomes

\begin{tabular}{|c|c|c|c|c|}
\hline & All $(\mathbf{n}=186)$ & RAX cannulation $(n=84)$ & Non-RAX cannulation $(n=102)$ & $P$ value \\
\hline \multicolumn{5}{|l|}{ Proximal repair } \\
\hline Supracoronary ascending replacement & $155(83.3)$ & $67(79.8)$ & $88(86.3)$ & .310 \\
\hline Aortic root replacement & $30(16.1)$ & $16(19.0)$ & $14(13.7)$ & .434 \\
\hline David operation & $1(0.5)$ & $1(1.2)$ & 0 & .922 \\
\hline \multicolumn{5}{|l|}{ Distal repair } \\
\hline Isolated ascending replacement & $118(63.4)$ & $53(63.1)$ & $65(63.7)$ & .949 \\
\hline Hemiarch replacement & $38(20.4)$ & $16(19.0)$ & $22(21.6)$ & .809 \\
\hline Total arch replacement & $30(16.1)$ & $15(17.9)$ & $15(14.7)$ & .703 \\
\hline Antegrade TEVAR & $2(1.1)$ & $1(1.2)$ & $1(1.0)$ & .565 \\
\hline CPB time (min) & $166(123 ; 217)$ & $178(125 ; 237)$ & $156(121 ; 203)$ & .075 \\
\hline CX time (min) & $102(82 ; 137)$ & $107(84 ; 146)$ & $98(81 ; 133)$ & .299 \\
\hline HCA time (min) & $29(19 ; 37)$ & $27(0 ; 38)$ & $29(24 ; 37)$ & .121 \\
\hline Antegrade cerebral perfusion & $79(42.5)$ & $48(57.1)$ & $31(30.4)$ & $<.001$ \\
\hline Deep hypothermic circulatory arrest & $107(57.5)$ & $36(42.9)$ & $71(69.6)$ & $<.001$ \\
\hline Lowest body temperature $\left({ }^{\circ} \mathrm{C}\right)$ & $20.0(18.6 ; 22.4)$ & $20.6(18.9 ; 23.3)$ & $19.9(18.6 ; 21.2)$ & .184 \\
\hline Reexploration for bleeding & $15(8.1)$ & $6(7.1)$ & $9(8.8)$ & .882 \\
\hline Stroke, new onset & $18(9.7)$ & $8(9.5)$ & $10(9.8)$ & .853 \\
\hline TND & $16(8.6)$ & $9(10.7)$ & $7(6.9)$ & .503 \\
\hline Renal failure & $17(9.1)$ & $6(7.1)$ & $11(10.8)$ & .991 \\
\hline Respiratory failure & $86(46.2)$ & $41(48.8)$ & $45(44.1)$ & .570 \\
\hline ICU time & $6(4 ; 10)$ & $6(3 ; 10)$ & $6(4 ; 10)$ & .866 \\
\hline In-hospital time & $20(14 ; 28)$ & $21(14 ; 29)$ & $20(14 ; 28)$ & .739 \\
\hline In-hospital mortality & $19(10.2)$ & $8(9.5)$ & $11(10.8)$ & .969 \\
\hline
\end{tabular}



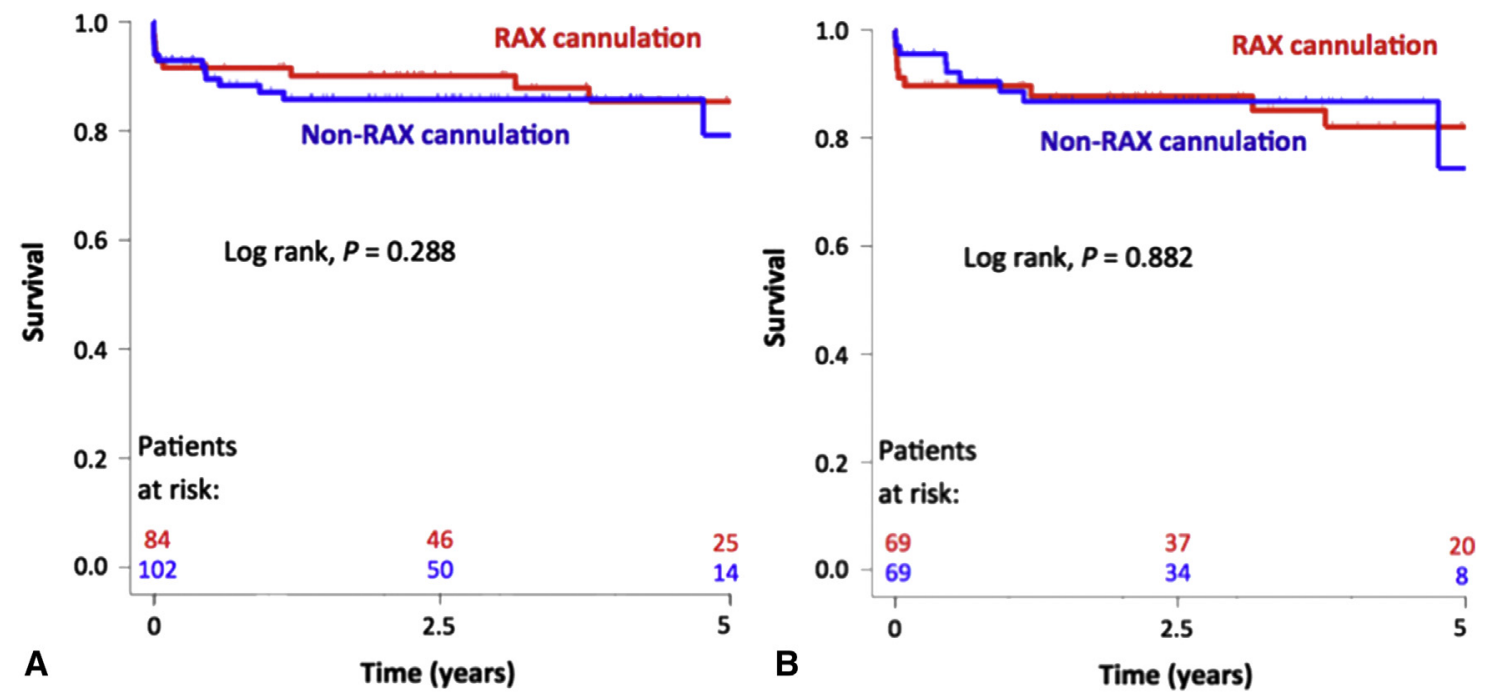

FIGURE 2. Survival after surgery for acute type A aortic dissection in (A) all and (B) propensity score-matched patients with dissected innominate artery. $R A X$, Right axillary.

non-RAX groups in the frequency of remodeling in primarily dissected arteries.

\section{Cannulation of Dissected Right Axillary Artery}

The RAX artery was cannulated in 8 patients with RAX, although it was dissected. Of those, 4 presented a concomitant right carotid artery dissection. The axillary artery was cannulated in all via a Dacron graft anastomosed end-to-side to the true lumen. None of those patients had a new-onset postoperative stroke or perioperative death. Reversible postoperative renal failure developed in 1 patient, and a transient ischemic attack developed in 1 patient. We observed a remodeled RAX artery at followup in 1 patient.

\section{Outcome in Matched Cohorts}

The standardized mean difference of all covariates included in the propensity score-matched analysis, with the exception of "at least 1 organ malperfusion" (standardized mean difference $=0.17$ ), was less than 0.1 , indicating that a good balance and successful bias reduction were achieved in both groups (Table 4). There were no group differences with regard to re-thoracotomy for bleeding (6\% vs $10 \%, P=.53)$, renal failure $(12 \%$ vs $13 \%$, $P=.82)$, respiratory failure ( $49 \%$ vs $44 \%, P=.44)$, and postoperative new-onset stroke ( $12 \%$ vs $10 \%, P=.78)$. In-hospital mortality was $11.6 \%$ in the matched RAX cases and $7.2 \%$ in the matched non-RAX cases $(P=.56)$ (Table 4). Survival did not differ between matched RAX and non-RAX cases (log rank, $P=.882$ ) (Figure $2, B$ ).

\section{DISCUSSION}

This study addresses whether RAX artery cannulation in type A aortic dissection with dissected innominate artery is safe. The RAX artery is one of the most popular cannulation sites in patients presenting with type A dissection. ${ }^{1}$ Previous reports have suggested the superiority of axillary cannulation versus femoral cannulation due to a decreased stroke risk, ${ }^{13,14}$ lower in-hospital mortality, ${ }^{5,6}$ and better long-term survival. ${ }^{15}$ However, there are no data revealing whether innominate artery dissection should be a contraindication for RAX artery cannulation.

Despite many improvements in treating acute type A aortic dissection, in-hospital mortality after surgery remains high, usually between $17 \%$ reported in the German Registry for Acute Aortic Dissection Type $\mathrm{A}^{8}$ and 24\% among patients in the International Registry of Acute Aortic Dissection, ${ }^{16}$ decreasing to $10 \%$ to $15 \%$ in most experienced hands. ${ }^{10-12,17,18}$ Perioperative mortality is strongly associated with malperfusion and varies depending on the number of organ systems affected (up to $43 \%$ in patients with 3 -organ malperfusion syndrome). ${ }^{19}$ The impaired flow in the brain-supplying arteries is one the most frequent manifestations of malperfusion ${ }^{20}$ and may lead to serious irreversible neurologic complications. The surgeon's cannulation strategy is a critical factor that defines organ perfusion during surgery and therefore may play a crucial role in the operative outcome. ${ }^{21}$

One could argue that innominate artery involvement in the dissection process is a contraindication for RAX cannulation because of the potential risk of false lumen expansion and true lumen collapse leading to multiorgan malperfusion, which is usually fatal. Our results show that the innominate artery is frequently $(45 \%)$ dissected in patients with type A aortic dissection. However, we observed no differences in short- and midterm outcomes in patients who did or did not undergo axillary cannulation in case of a dissected innominate artery. Moreover, we 
TABLE 4. Propensity score-matched patients characteristic and outcome

\begin{tabular}{|c|c|c|c|c|}
\hline & $\begin{array}{c}\text { RAX } \\
\text { cannulation } \\
(\mathbf{n}=69)\end{array}$ & $\begin{array}{c}\text { Non-RAX } \\
\text { cannulation } \\
(n=69)\end{array}$ & $\begin{array}{c}P \\
\text { value }\end{array}$ & SMD \\
\hline \multicolumn{5}{|l|}{ Characteristic } \\
\hline Age (y) & $61(51 ; 69)$ & $63(53 ; 71)$ & .443 & 0.013 \\
\hline Male gender & $40(58.0)$ & $38(55.1)$ & .730 & -0.058 \\
\hline MFS & $4(5.8)$ & $5(7.2)$ & 1.000 & 0.058 \\
\hline Cardiogenic shock & $5(7.2)$ & $4(5.8)$ & 1.000 & -0.058 \\
\hline Cardiac tamponade & $4(5.8)$ & $3(4.3)$ & 1.000 & -0.065 \\
\hline $\begin{array}{c}\text { At least } 1 \text { organ } \\
\text { malperfusion }\end{array}$ & $26(37.7)$ & $32(46.4)$ & .301 & 0.170 \\
\hline Aortic root replacement & $8(11.6)$ & $9(13.0)$ & .793 & 0.043 \\
\hline Aortic arch replacement & $15(21.7)$ & $10(14.5)$ & .272 & -0.180 \\
\hline \multicolumn{5}{|l|}{ Outcome } \\
\hline Reexploration for bleeding & $4(5.8)$ & $7(10.1)$ & .530 & \\
\hline Stroke, new onset & $8(11.6)$ & $7(10.1)$ & 1.000 & \\
\hline TND & $8(11.6)$ & $5(7.2)$ & .560 & \\
\hline Renal failure & $8(11.6)$ & $9(13.0)$ & .589 & \\
\hline Respiratory failure & $34(49.3)$ & $30(43.5)$ & .451 & \\
\hline ICU time & $9(3 ; 10)$ & $9(4 ; 10)$ & .635 & \\
\hline In-hospital time & $27(14 ; 30)$ & $29(17 ; 30)$ & .806 & \\
\hline In-hospital mortality & $8(11.6)$ & $5(7.2)$ & .560 & \\
\hline
\end{tabular}

Categoric values are $\mathrm{n}(\%)$, and continuous values are median (first quartile; third quartile). RAX, Right axillary; SMD, standardized mean difference; MFS, Marfan syndrome; $T N D$, temporary neurologic dysfunction; $I C U$, Intensive care unit.

observed no postoperative adverse events associated with axillary artery cannulation in patients with a dissected axillary artery. However, in case of entry located in the innominate artery, CPB inflow via the RAX artery may pressurize the false lumen and therefore lead to false lumen expansion and true lumen collapse (Figure 3). This is usually noticed shortly after CPB initiation because of low CPB flow caused by high arterial resistance or a decrease in near-infrared spectroscopy. It is not possible to definitively exclude dissection entries in peripheral arteries such as the innominate artery in CT. However, whenever there is high arterial resistance at the beginning of CPB circulation, or the near-infrared spectroscopy decreases, and the patient is cannulated via the RAX artery in the presence of dissection involving the innominate artery, the previously mentioned pathogenic mechanisms must be considered and a secondary arterial cannulation site should be performed immediately. We observed this complication in 1 patient with aortic rupture similar to cases described in the literature. ${ }^{22,23}$ Moreover, 25 patients with RAX were cannulated for different reasons, including surgeon's preference, patients' obesity, and limb ischemia prevention, at 2 different sites simultaneously, which might have prevented true lumen collapse if there was an entry in the innominate artery (Figure 3). Because of the retrospective study design, it is not possible to give a definitive number of patients whose second cannulation was unavoidable to provide adequate CPB flow.

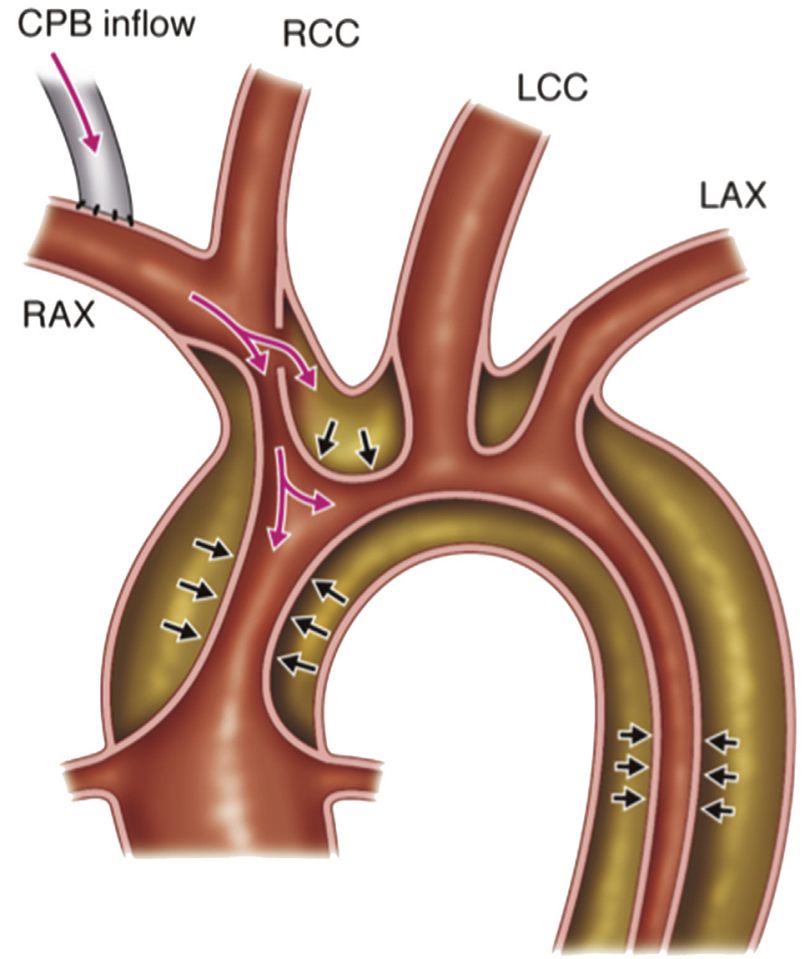

FIGURE 3. Hypothetical pathomechanism of false lumen expansion and true lumen collapse after cannulation of the axillary artery in case of entry tear in the innominate artery. CPB inflow through the RAX artery may pressurize via the entry tear the false lumen and lead to true lumen collapse, which is usually noticed by high arterial resistance and low CPB flow. $C P B$, Cardiopulmonary bypass; $R C C$, right common carotid; $L C C$, left common carotid; $L A X$, left axillary; $R A X$, right axillary.

The literature on remodeling the peripheral arteries after surgery for type A dissection is limited to coronary arteries remodeling after iatrogenic dissection due to catheter manipulations. ${ }^{24,25}$ In our study, we analyzed follow-up changes in dissection extending into arteries coming off the aorta. We observed no significant difference in the remodeling frequency in primarily dissected peripheral arteries in conjunction with the cannulation site. The highest remodeling rate $(26 \%)$ was observed in the primarily dissected right carotid artery in the non-RAX group. However, this was not significantly different from the remodeling observed in RAX group.

\section{CONCLUSIONS}

Our findings support using the axillary artery for arterial inflow for the heart-lung machine regardless of innominate artery involvement in the dissection process.

\section{Conflict of Interest Statement}

Authors have nothing to disclose with regard to commercial support. 


\section{References}

1. Rylski B, Urbanski PP, Siepe M, Beyersdorf F, Bachet J, Gleason TG, et al. Operative techniques in patients with type A dissection complicated by cerebral malperfusion. Eur J Cardiothorac Surg. 2014;46:156-66.

2. Villard J, Froment JC, Milleret R, Dureau G, Amouroux C, Boivin J, et al. Type I, complete, acute aortic dissection. Value of arterial perfusion by the axillary route. Ann Chir Thorac Cardiovasc. 1976;15:133-5.

3. Sabik JF, Lytle BW, McCarthy PM, Cosgrove DM. Axillary artery: an alternative site of arterial cannulation for patients with extensive aortic and peripheral vascular disease. J Thorac Cardiovasc Surg. 1995;109:885-90.

4. Strauch JT, Spielvogel D, Lauten A, Lansman SL, McMurtry K, Bodian CA, et al. Axillary artery cannulation: routine use in ascending aorta and aortic arch replacement. Ann Thorac Surg. 2004;78:103-8.

5. Benedetto U, Mohamed H, Vitulli P, Petrou M. Axillary versus femoral arterial cannulation in type A acute aortic dissection: evidence from a meta-analysis of comparative studies and adjusted risk estimates. Eur J Cardiothorac Surg. 2015; 48:953-9.

6. Ren Z, Wang Z, Hu R, Wu H, Deng H, Zhou Z, et al. Which cannulation (axillary cannulation or femoral cannulation) is better for acute type A aortic dissection repair? A meta-analysis of nine clinical studies. Eur J Cardiothorac Surg. 2015;47:408-15.

7. Erbel R, Aboyans V, Boileau C, Bossone E, Bartolomeo RD, Eggebrecht H, et al. 2014 ESC Guidelines on the diagnosis and treatment of aortic diseases: document covering acute and chronic aortic diseases of the thoracic and abdominal aorta of the adult. The Task Force for the Diagnosis and Treatment of Aortic Diseases of the European Society of Cardiology (ESC). Eur Heart J. 2014;35:2873-926.

8. Rylski B, Hoffmann I, Beyersdorf F, Suedkamp M, Siepe M, Nitsch B, et al. Acute aortic dissection type A: age-related management and outcomes reported in the German Registry for Acute Aortic Dissection Type A (GERAADA) of over 2000 patients. Ann Surg. 2014;259:598-604.

9. Rylski B, Beyersdorf F, Kari FA, Schlosser J, Blanke P, Siepe M. Acute type A aortic dissection extending beyond ascending aorta: limited or extensive distal repair. J Thorac Cardiovasc Surg. 2014;148:949-54.

10. Rylski B, Beyersdorf F, Blanke P, Boos A, Hoffmann I, Dashkevich A, et al. Supracoronary ascending aortic replacement in patients with acute aortic dissection type A: what happens to the aortic root in the long run? J Thorac Cardiovasc Surg. 2013;146:285-90.

11. Tanaka M, Kimura N, Yamaguchi A, Adachi H. In-hospital and long-term results of surgery for acute type A aortic dissection: 243 consecutive patients. Ann Thorac Cardiovasc Surg. 2012;18:18-23.

12. Kimura N, Tanaka M, Kawahito K, Itoh S, Okamura H, Yamaguchi A, et al. Early- and long-term outcomes after surgery for acute type a aortic dissection in patients aged 45 years and younger. Circ J. 2011;75:2135-43.

13. Etz CD, Plestis KA, Kari FA, Silovitz D, Bodian CA, Spielvogel D, et al. Axillary cannulation significantly improves survival and neurologic outcome after atherosclerotic aneurysm repair of the aortic root and ascending aorta. Ann Thorac Surg. 2008;86:441-7.

14. Haldenwang PL, Wahlers T, Himmels A, Wippermann J, Zeriouh M, Kröner A, et al. Evaluation of risk factors for transient neurological dysfunction and adverse outcome after repair of acute type A aortic dissection in 122 consecutive patients. Eur J Cardiothorac Surg. 2012;42:e115-20.

15. Etz CD, von Aspern K, da Rocha E, Silva J, Girrbach FF, Leontyev S, et al Impact of perfusion strategy on outcome after repair for acute type a aortic dissection. Ann Thorac Surg. 2014;97:78-85.

16. Rampoldi V, Trimarchi S, Eagle KA, Nienaber CA, Oh JK, Bossone E, et al International Registry of Acute Aortic Dissection (IRAD) Investigators. Simple risk models to predict surgical mortality in acute type A aortic dissection: the International Registry of Acute Aortic Dissection score. Ann Thorac Surg. 2007;83:55-61.

17. Halstead JC, Spielvogel D, Meier DM, Rinke S, Bodian C, Malekan R, et al Composite aortic root replacement in acute type A dissection: time to rethink the indications? Eur J Cardiothorac Surg. 2005;27:626-32.

18. Rylski B, Bavaria JE, Milewski RK, Vallabhajosyula P, Moser W, Kremens E, et al. Long-term results of neo-media sinus Valsalva repair in 489 patients with type A aortic dissection. Ann Thorac Surg. 2014;98:582-8.

19. Czerny M, Schoenhoff F, Etz C, Englberger L, Khaladj N, Zierer A, et al The impact of pre-operative malperfusion on outcome in acute type a aortic dissection: results from the GERAADA Registry. J Am Coll Cardiol. 2015;65: 2628-35.

20. Girdauskas E, Kuntze T, Borger MA, Falk V, Mohr FW. Surgical risk of pre-operative malperfusion in acute type A aortic dissection. J Thorac Cardiovasc Surg. 2009;138:1363-9.

21. Suzuki T, Asai T, Matsubayashi K, Kambara A, Kinoshita T, Hiramatsu N, et al Safety and efficacy of central cannulation through ascending aorta for type A aortic dissection. Interact Cardiovasc Thorac Surg. 2010;11:34-7.

22. Imanaka K, Kyo S, Tanabe H, Ohuchi H, Asano H, Yokote Y. Fatal intraoperative dissection of the innominate artery due to perfusion through the right axillary artery. J Thorac Cardiovasc Surg. 2000;120:405-6.

23. Schachner T, Nagiller J, Zimmer A, Laufer G, Bonatti J. Technical problems and complications of axillary artery cannulation. Eur J Cardiothorac Surg. 2005;27: 634-7.

24. Perek B, Lesiak M, Jemielity M. Spontaneous resolution of iatrogenic dissection of the left main coronary artery extending to the thoracic and abdominal aorta. Postepy Kardiol Interwencyjnej. 2013;9:194-7.

25. Núñez-Gil IJ, Bautista D, Cerrato E, Salinas P, Varbella F, Omedè P, et al Incidence, management, and immediate- and long-term outcomes after iatrogenic aortic dissection during diagnostic or interventional coronary procedures. Circulation. 2015;131:2114-9.

Key Words: aortic dissection, cerebral ischemia, stroke 


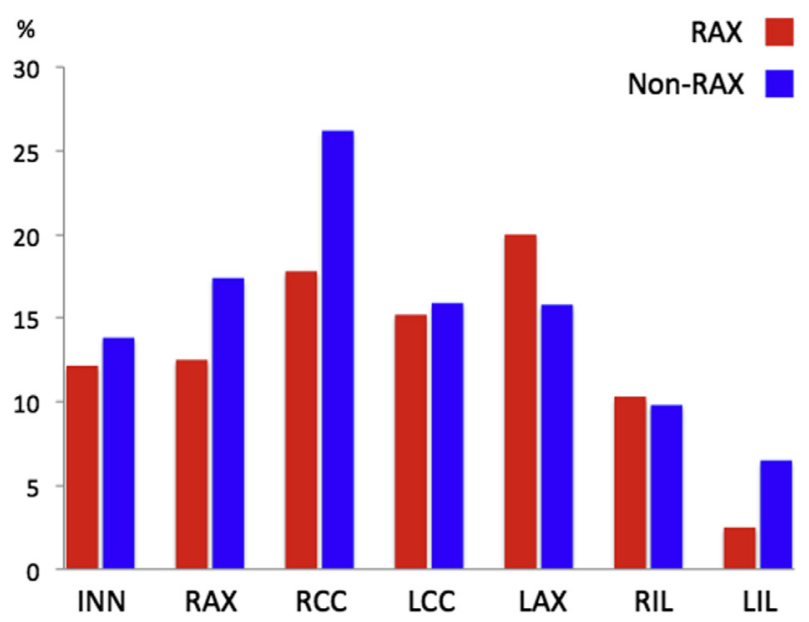

FIGURE E1. Remodeling of primarily dissected arteries. There is no significant difference in remodeling incidence in primarily dissected arteries between RAX and non-RAX cases. Arterial remodeling is defined as a lack of dissection or intramural hematoma in the artery, which was dissected or had intramural hematoma at the initial CT angiography with an acute type A aortic dissection. $R A X$, Right axillary; $I N N$, innominate artery; $R C C$, right common carotid; $L C C$, left common carotid; $L A X$, left axillary; $R I L$, right iliac; $L I L$, left iliac. 